\title{
Thrombectomy 6 to 24 hours after Stroke using Alberta Stroke Program Early CT Score (ASPECTS)
}

A. De Sousa1, I. Fragata2 ${ }^{2}$ S. Galego ${ }^{3}$, B. Maia ${ }^{3}$, C. Sousa 3 , A. Paiva Nunes ${ }^{3}$

1 Neurology Department, Centro Hospitalar de Lisboa Central - Hospital Sto. António dos Capuchos, Lisbon (Portugal)

2 Neuroradiology, Centro Hospitalar de Lisboa Central - Hospital de S. José, Lisbon (Portugal)

3 Unidade Cerebro Vascular, Centro Hospitalar de Lisboa Central - Hospital de S. José, Lisbon (Portugal)

\section{Background}

DAWN trial recently established the benefit of mechanical thrombectomy for patients with occlusion of intracranial internal carotid (ICA) or middle cerebral artery (MCA), last known to be well 6 to 24 hours earlier with deficit-infarct mismatch.

\section{Objective}

To determine outcomes for mechanical thrombectomy (MT) performed at our center 6 to 24 hours after stroke with ASPECTS $\geq$ 7 instead of deficit-infarct mismatch.

\section{Methods}

Analysis of extracted data, between 2013 and 2017, from local Safe Implementation of Treatment in Stroke (SITS) registry.

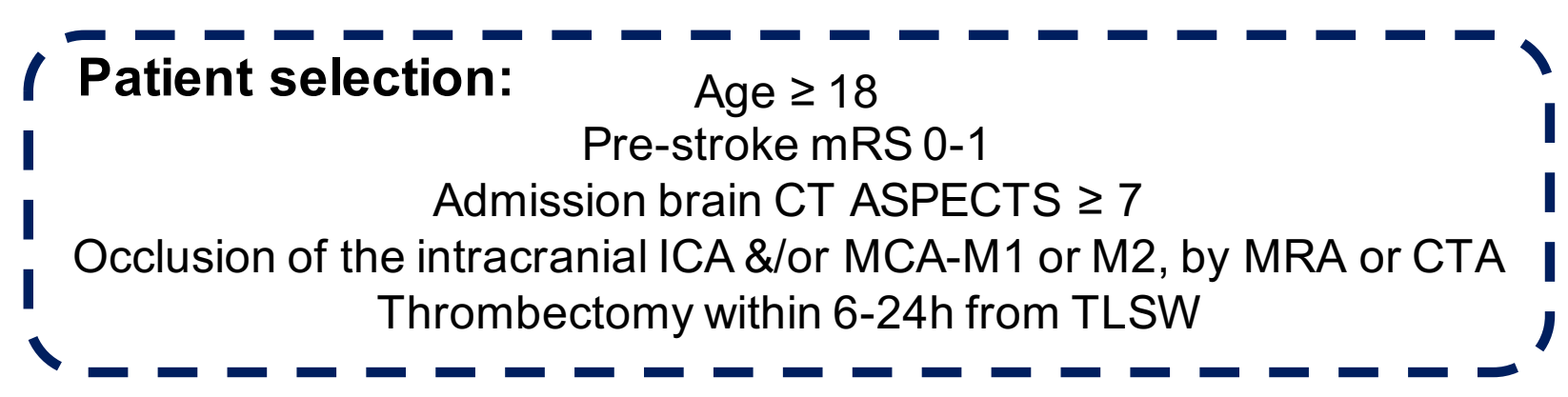

TLSW: time last seen well

ASPECTS calculated by a neuroradiologist blinded to clinical outcome.

Primary outcome: Functional independence (modified Rankin score $\leq 2$ at 90 days)

\section{Results}

We identified a total of 43 patients.

\begin{tabular}{|l|r|r|}
\hline Table 1. Baseline characteristics $(\mathbf{n}=\mathbf{4 3})$ & \\
\hline Variable & Our study & DAWN MT $^{1}$ \\
\hline Age at stroke onset (yr) - median, SD & $69,7 \pm 12,9$ & $69,4 \pm 14.1$ \\
\hline Age $\geq 80$ years - no. (\%) & $8(18,6)$ & $25(23 \%)$ \\
\hline Male sex - no. (\%) & $21(48,8)$ & $42(39 \%)$ \\
\hline NIHSS score (median, IQR) & $14(9-19)$ & $17(13-21)$ \\
\hline 10 - 20 - no. (\%) & $31(72,1)$ & $78(73)$ \\
\hline ASPECTS (median, IQR) & $9(8-9)$ & NA \\
\hline Occlusion site - no. (\%) & & \\
\hline \multicolumn{1}{|c|}{ Intracranial ICA } & $7(16,3)$ & $22(21)$ \\
\hline MCA-M1 & $24(55,8)$ & $83(78)$ \\
\hline MCA-M2 & $12(27,9)$ & $2(2)$ \\
\hline
\end{tabular}

Figure 1. Cardiovascular risk factors

(IS: ischemic stroke; TIA: transientischemic attack)

100\% $76,7 \%$

$75 \%$

$50 \%$

$25 \%$

$20,9 \%$

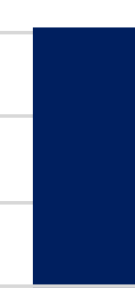
$44,2 \%$

$0 \%$
$16,3 \%$
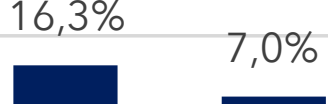

$20,9 \%$
Figure 2. Type of stroke onset

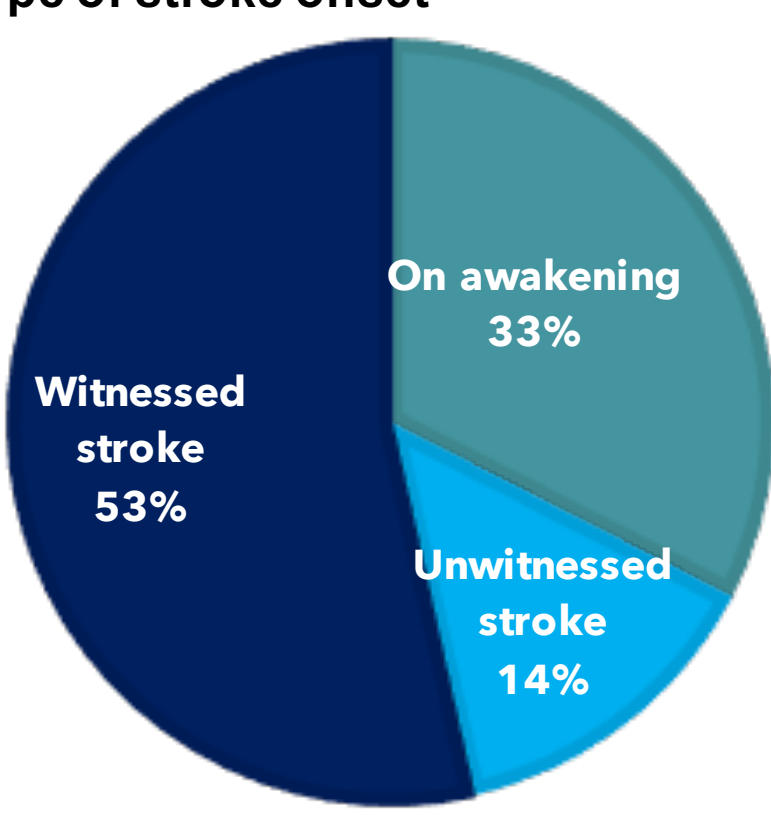

DAWN MT group

On awakening: $63 \%$

Unwitnessed stroke $27 \%$

Witnessed stroke: 10\%

- - - - - - - - - '

\section{Table 2. Treatment}

Variable

Treatment with IV alteplase - no. (\%)

Interval between TLSW and groin puncture (median, IQR)

Our study

DAWN MT ${ }^{1}$

Figure 3. Functional status at 90 days

$100 \%$

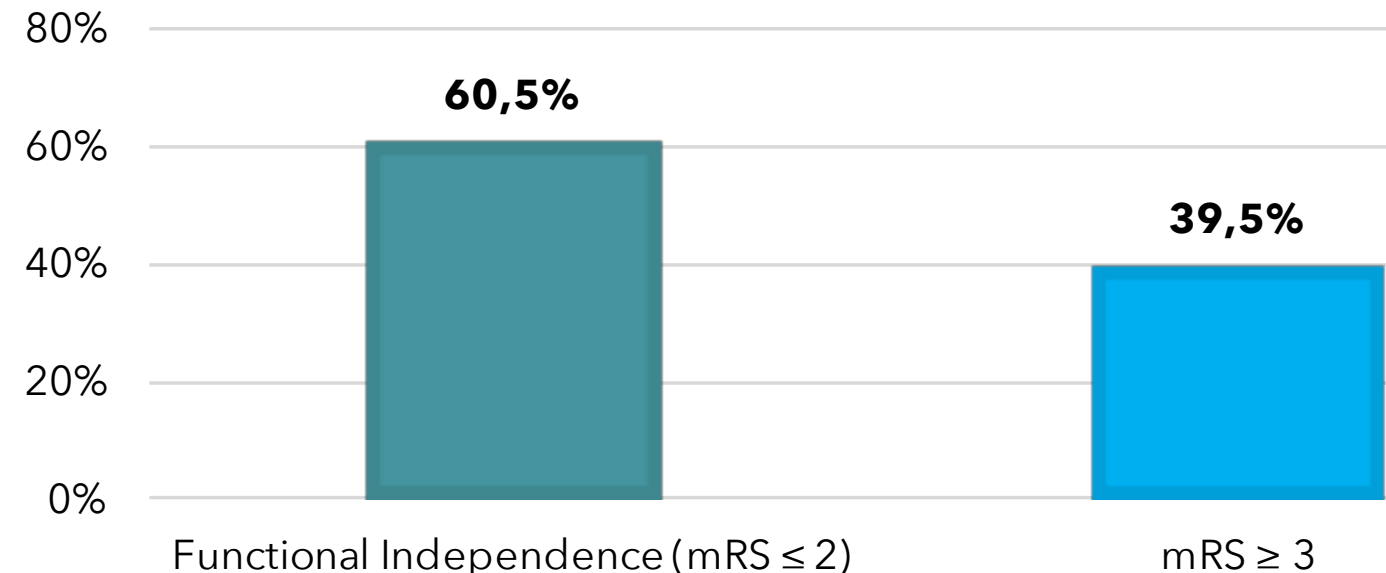

No difference in functional independence at 90 days between patients younger and older than 80 years $(p=.69)$, and patients with TLSW $\leq$ and above $12 \mathrm{~h}(\mathrm{p}=.26)$.

\section{Table 3. Secondary outcomes}

\section{Variable}

Early response - no. (\%) $\S$

Our study DAWN MT ${ }^{1}$

Post MT TICl $2 \mathrm{~b}$ or $3-$ no. (\%) \pm

$19(44,2) \quad 51(48)$

Death from any cause at 90 days - no. $(\%)$

$39(90,7) \quad 90(84)$

Symptomatic intracranial haemorrhage at $24 \mathrm{~h}$

$4(9,3) \quad 20(19)$

- no. (\%) II

$1(2,3)$

Neurologic deterioration at $24 \mathrm{~h}-$ no. (\%) $\int s$

$1(2,3)$

$15(14)$

$\$$ Early response: decrease in the NIHSS of $\geq 10$ pts from baseline or an NIHSS of 0 or 1 on day 5, 6, or 7 of hospitalization or at discharge if it occurred before day 5 .

\pm The modified Thrombolysis in Cerebral Infarction ( $\mathrm{mTICl}$ ) scale ranges from $0-3$, with grade of $2 \mathrm{~b}$ or 3 indicating reperfusion of $>50 \%$ of the affected territory

II Symptomatic intracranial hemorrhage - presence of extravascular blood in the cranium associated with an increase in the NIHSS of $\geq 4$ pts or death and judged to be the predominant cause of neurologic deterioration.

$\iint$ Neurologic deterioration - an increase in the NIHSS of $\geq 4$ pts within 5 days after stroke that was not attributed to intracranial hemorrhage or malignant cerebral edema.

\section{Conclusion}

In our series, patients with ischemic stroke last known to be well 6 to 24 hours earlier and an ASPECTS $\geq 7$ treated with MT, functional independence rate at 90 days was similar to DAWN trial result $(60,5 \%$ vs. $49 \%)$

Further research is needed to determine reliability of the ASPECTS in assessing favorable outcome for this time-window. 